\title{
Influence of Crucible Thermal Conductivity on Crystal Growth in an Industrial Directional Solidification Process for Silicon Ingots
}

\author{
Zaoyang Li, ${ }^{1,2}$ Lijun Liu, ${ }^{1}$ Yunfeng Zhang, ${ }^{3}$ and Genshu Zhou ${ }^{2}$ \\ ${ }^{1}$ School of Energy and Power Engineering, Xian Jiaotong University, Xian, Shaanxi 710049, China \\ ${ }^{2}$ State Key Laboratory for Mechanical Behavior of Materials, Xian Jiaotong University, Xi'an, Shaanxi 710049, China \\ ${ }^{3}$ Yingli Green Energy Holding Co., Ltd., Baoding, Hebei 071051, China \\ Correspondence should be addressed to Lijun Liu; ljliu@mail.xjtu.edu.cn
}

Received 7 December 2015; Accepted 7 March 2016

Academic Editor: Yanfa Yan

Copyright ( 2016 Zaoyang Li et al. This is an open access article distributed under the Creative Commons Attribution License, which permits unrestricted use, distribution, and reproduction in any medium, provided the original work is properly cited.

\begin{abstract}
We carried out transient global simulations of heating, melting, growing, annealing, and cooling stages for an industrial directional solidification (DS) process for silicon ingots. The crucible thermal conductivity is varied in a reasonable range to investigate its influence on the global heat transfer and silicon crystal growth. It is found that the crucible plays an important role in heat transfer, and therefore its thermal conductivity can influence the crystal growth significantly in the entire DS process. Increasing the crucible thermal conductivity can shorten the time for melting of silicon feedstock and growing of silicon crystal significantly, and therefore large thermal conductivity is helpful in saving both production time and power energy. However, the high temperature gradient in the silicon ingots and the locally concave melt-crystal interface shape for large crucible thermal conductivity indicate that high thermal stress and dislocation propagation are likely to occur during both growing and annealing stages. Based on the numerical simulations, some discussions on designing and choosing the crucible thermal conductivity are presented.
\end{abstract}

\section{Introduction}

The photovoltaics (PV) power generation is developing rapidly and the annual growth rate of PV installations is $44 \%$ during the past 10 years [1]. Silicon-wafer based PV technology accounts for more than $90 \%$ of the total production and the share of multicrystalline silicon (mc-Si) technology is more than 60\% [2]. Directional solidification (DS) is the main method for manufacturing mc-Si ingots for solar cells. The DS is a highly coupled nonlinear crystal growth process with complex heat and mass transport. It includes thermal conduction, convection, radiation, phase change, and transport of different impurities $[3,4]$. These transport characteristics can influence the crystal growth of silicon ingots significantly [5]. To control the heat and mass transport and optimize the crystal growth, the component materials in the DS furnace are carefully chosen. For example, the insulations between the core region and the water-cooled furnace wall are made of carbon felt with small thermal conductivity, which is beneficial for the reduction of heating power [6]. The heat exchange block below the silicon domain is made of graphite with large thermal conductivity, which is helpful in releasing heat during crystal growth and providing a driving force for solidification. Besides, the crucible in contact with the silicon region can influence the crystal growth directly, and therefore much more attention is paid to the crucible materials.

The crucible is usually made of quartz $\left(\mathrm{SiO}_{2}\right)$ and internally coated with a high-purity layer such as silicon nitride $\left(\mathrm{Si}_{3} \mathrm{~N}_{4}\right)$ to prevent the impurity contamination from crucible wall [7]. Some researchers also propose the application of silicon nitride crucible, as it can be reused and the source of oxygen contamination is eliminated [8]. The crucible thermal conductivity is usually small and the corresponding thermal resistance is large. As a result, the change of thermal conductivity can influence the heat flux in the silicon region and modify the crystal growth process significantly. Miyazawa et al. [9] numerically investigated the influence of thermal 


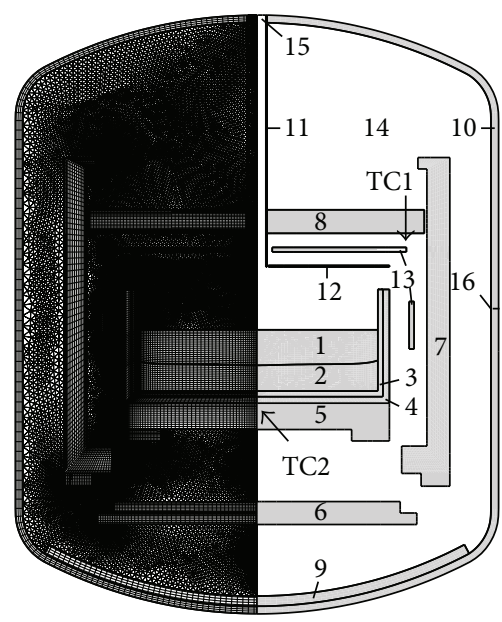
(1) Melt
(2) Crystal
(3) Crucible
(4) Susceptor
(5) Heat exchange block
(6)-(8) Insulations
(9) Insulated pad
(10) Wall
(11) Argon tube
(12) Cover
(13) Heaters
(14) Argon domain
(15) Argon inlet
(16) Argon outlet

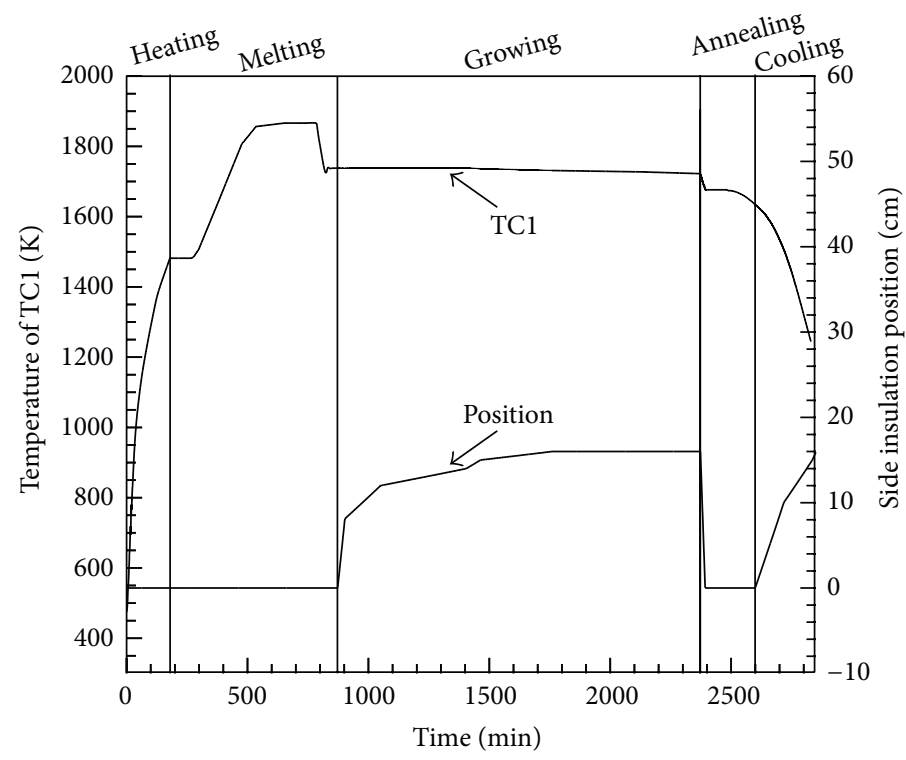

(a)

(b)

FIGURE 1: Model of an industrial-size DS furnace: (a) configurations and computational grids; (b) process control parameters.

conductivity of the crucible wall on the melt-crystal interface shape and found that the interface shape is very sensitive to the thermal conductivity due to the modification of outgoing heat flux through the crucible wall. Chen et al. [10] showed that the changes of melt-crystal interface and temperature gradient due to different crucible thermal conductivities have significant influence on the thermal stress and dislocations in the silicon ingot. For different crucible materials, Bellmann et al. [11] found that the difference between the thermal conductivity of quartz and silicon nitride crucibles can lead to different thermal histories during the melting and growing stages of the DS process. Schneider et al. [12] reused the nitride bonded silicon nitride crucible for DS of silicon ingots and inferred that thermal conductivity can influence the growth interface shape. Zhao et al. [13] even proposed a silicon nitride and quartz composited crucible to adjust the thermal conductivity and improve the crystal growth. These studies are helpful in understanding the important role of the crucible thermal conductivity, but they are not sufficient to reveal the influence of thermal conductivity on crystal growth through the entire DS process for industrialsize silicon ingots.

In this paper, we choose an industrial DS furnace that can produce $450 \mathrm{~kg}$ ingots to numerically study the effects of crucible thermal conductivity on silicon crystal growth. The characteristics of heat transfer for the entire DS process including the heating, melting, growing, annealing, and cooling stages are analyzed for crucibles with different thermal conductivities. The heating power consumption, temperature distribution, melting time and sequence, solidification front surface shape, and other process parameters are compared. The study can help us to deeply understand the silicon crystal growth by the DS method and provide useful advice for growing high-quality silicon ingots by using crucible with appropriate thermal conductivity.

\section{Model Description}

The configuration, dimensions, and computational grids of the industrial-size DS furnace for silicon ingots are shown in Figure 1(a). The thickness and side length of the square crucible are 0.02 and $0.84 \mathrm{~m}$, respectively. The height of the silicon ingot is about $0.25 \mathrm{~m}$. The thermocouple TC1 located close to the top heater is used to control the heating power by monitoring the temperature evolution, and the thermocouple TC2 is used to monitor the temperature evolution below the crucible. The crucible is labeled with No. 3 and its thermal conductivity can be easily changed by adjusting the porosity or using different materials [11, 13]. The entire furnace is divided into a number of subdomains for simulation and the structured/unstructured combined mesh scheme is applied to improve the computation efficiency.

The control parameters for the entire DS process are shown in Figure 1(b). Four vertical thin solid lines divide the curve sections into heating, melting, growing, annealing, and cooling stages. The side insulation, labeled with No. 7 in Figure 1(a), is closed to prevent heat loss during the heating, melting, and annealing stages, and the corresponding 
position is zero in Figure 1(b). It is opened to allow heat escaping for the growing and cooling stages. The temperature of TC1 is preset to control the heating power from melting to cooling stages. It is determined by the automatically increased heating power in the heating stage. The TC1 setting, the side insulation moving velocity, the furnace pressure, and the argon flow rate are maintained the same for all the cases.

Transient simulations of global heat transfer, including melt convection, argon flow, thermal conduction, radiation, and phase change, are carried out for the entire DS process. The basic assumptions for the transient global model have been published elsewhere [14]. An enthalpy formulation based on fixed-grid methodology is used to model the phase change and accurately track the interface evolution during the melting and growing stages [15]. The governing equations for the silicon domain in the crucible are

$$
\begin{aligned}
\nabla \cdot \vec{u} & =0 \\
\rho \frac{\partial \vec{u}}{\partial t}+\rho \vec{u} \cdot \nabla \vec{u} & =-\nabla p+\nabla \cdot\left[\mu\left(\nabla \vec{u}+\nabla \vec{u}^{T}\right)\right] \\
& -\frac{\rho \vec{g} \beta\left(h-h_{\mathrm{ref}}\right)}{C_{p}}+S_{m} \\
\rho \frac{\partial(h)}{\partial t}+\rho \nabla \cdot(\vec{u} h)= & \nabla \cdot\left(\frac{\lambda}{C_{p}} \nabla h\right)+S_{h}
\end{aligned}
$$

where $\vec{u}$ is the velocity, $\rho$ is the density, $t$ is the time, $p$ is the pressure, $\mu$ is the dynamic viscosity, $\vec{g}$ is the gravity acceleration vector, $\beta$ is the thermal expansion coefficient, $h$ is the sensible enthalpy, $h_{\text {ref }}$ is the reference sensible enthalpy, and $C_{p}$ is the specific heat capacity. The source term $S_{m}$ is used to drop the velocity to zero when the silicon in a grid cell changes from melt to solid. The source term $S_{h}$ accounts for the rate of volumetric latent heat change during phase change. The description of these two source terms can be found in [15].

All domains in Figure 1(a) are fully coupled in the numerical model. Zero radial gradients for all the variables, except for the radial velocity, are applied along the centerline of the furnace. Temperature continuity and heat flux conservation are kept at all interior boundaries between any two different domains. No-slip condition is applied at all the walls in the argon gas and silicon melt domains. Along the melt free surface, both the normal velocity component and shear stress are set to zero. The temperature of the furnace outer wall is assumed to be $300 \mathrm{~K}$. The inlet temperature and pressure of argon gas are set to $300 \mathrm{~K}$ and $60000 \mathrm{~Pa}$, respectively. The above model is established by using the software FLUENT, and it has been validated by comparing the numerical results with the experimental data [16].

The crucible thermal conductivity can be varied in a large range in different studies and for different materials $[6,9-13,17]$. Besides, the crucible thermal conductivity can also be changed by adjusting the porosity. Therefore, the 2$6 \mathrm{~W} / \mathrm{m} \cdot \mathrm{K}$ is selected as a typical range to study its influence on the silicon crystal growth during DS process. The range represents quartz crucible in this study, as other quartz physical parameters, such as density and specific heat, are used in the simulation. The thermophysical properties of all the component materials are listed in Table 1. It is known that the graphite can be used to manufacture susceptor, heat exchange block, argon tube, cover, and heaters, as shown in Figure 1(a). The carbon felt and the stainless steel are used to manufacture insulations and furnace wall, respectively.

\section{Results and Discussion}

3.1. Effect of Crucible Thermal Conductivity in the Heating and Melting Stages. Figure 2(a) shows the evolutions of temperature and heating power in the heating and melting stages for DS processes with different crucible thermal conductivities. The vertical thin solid line is the boundary between these two stages. The heating stage lasts from 0 to $180 \mathrm{~min}$ and the melting stage lasts from 180 to $870 \mathrm{~min}$. The heating power increases automatically to guarantee that the temperature of $\mathrm{TC1}$ can reach $1480 \mathrm{~K}$ at the end of heating stage, as shown in Figure 1(b), and then it is controlled by the preset TC1 during the melting stage. It can be seen from Figure 2(a) that the large differences of temperature and heating power among the three cases appear after about 460 min when the silicon feedstock begins to melt. This is because the crucible thermal conductivity influences the amount of heat transferred into the silicon domain and changes the melting rate, which will result in different heat absorption rates and influence the temperature distribution and heating power consumption.

To study the effect of crucible thermal conductivity on the melting of silicon feedstock in detail, Figure 2(b) shows the partial enlarged view of the rectangular zone indicated in Figure 2(a). Taking the dashed line representing $4 \mathrm{~W} / \mathrm{m} \cdot \mathrm{K}$ as an example, the temperature at the silicon top surface increases rapidly until $460 \mathrm{~min}$, when it reaches the melting point of $1685 \mathrm{~K}$ and the feedstock begins to melt from the top. The temperature increases relatively slowly from 460 to $755 \mathrm{~min}$, as the feedstock absorbs heat during melting. There is another turning point at about $755 \mathrm{~min}$ when the temperature begins to increase rapidly again after complete melting. Therefore, the time spent on the feedstock melting is about $295 \mathrm{~min}$ under the condition of $4 \mathrm{~W} / \mathrm{m} \cdot \mathrm{K}$. For the DS processes with crucible thermal conductivity of 2 and $6 \mathrm{~W} / \mathrm{m} \cdot \mathrm{K}$, the melting stages last from 460 to $790 \mathrm{~min}$ and from 460 to $725 \mathrm{~min}$, respectively. The corresponding total time is 330 and $265 \mathrm{~min}$, respectively. The data means that increasing the crucible thermal conductivity from 2 to $6 \mathrm{~W} / \mathrm{m} \cdot \mathrm{K}$ can shorten the melting time by $65 \mathrm{~min}$. This is because small thermal conductivity blocks the heat transferred from heaters to silicon domain, while large thermal conductivity can enhance the heat transfer and lead to fast melting. More heating power is needed to meet the large amount of heat absorption during fast melting, and this is also evidenced by the distributions of power profiles during melting in Figure 2(a).

Figure 3 shows the evolution of solid-liquid interface during the melting of silicon feedstock for DS processes with crucible thermal conductivity of 2 and $6 \mathrm{~W} / \mathrm{m} \cdot \mathrm{K}$. Figures 3(a1) and 3(b1) show that the feedstock starts melting from top for both cases at the initial stage. Next, the feedstock near the crucible side wall begins to melt, as shown in 
TABLE 1: Thermophysical properties of materials.

\begin{tabular}{|c|c|c|}
\hline Material & Variable & Value \\
\hline \multirow{4}{*}{ Quartz } & Density $\left(\mathrm{kg} / \mathrm{m}^{3}\right)$ & 1930 \\
\hline & Specific heat $(\mathrm{J} / \mathrm{kg} \cdot \mathrm{K})$ & 1059 \\
\hline & Thermal conductivity $(\mathrm{W} / \mathrm{m} \cdot \mathrm{K})$ & $2-6$ \\
\hline & Emissivity & 0.6 \\
\hline \multirow{4}{*}{ Graphite } & Density $\left(\mathrm{kg} / \mathrm{m}^{3}\right)$ & 1790 \\
\hline & Specific heat $(\mathrm{J} / \mathrm{kg} \cdot \mathrm{K})$ & 1800 \\
\hline & Thermal conductivity $(\mathrm{W} / \mathrm{m} \cdot \mathrm{K})$ & 140 \\
\hline & Emissivity & 0.8 \\
\hline \multirow{4}{*}{ Carbon felt } & Density $\left(\mathrm{kg} / \mathrm{m}^{3}\right)$ & 160 \\
\hline & Specific heat $(\mathrm{J} / \mathrm{kg} \cdot \mathrm{K})$ & $-317+4.0 T-2.4 \times 10^{-3} T^{2}+5.1 \times 10^{-7} T^{3}$ \\
\hline & Thermal conductivity $(\mathrm{W} / \mathrm{m} \cdot \mathrm{K})$ & $0.37-2.01 \times 10^{-4} \mathrm{~T}+2.37 \times 10^{-7} T^{2}-2.08 \times 10^{-11} T^{3}$ \\
\hline & Emissivity & 0.8 \\
\hline \multirow{4}{*}{ Stainless steel } & Density $\left(\mathrm{kg} / \mathrm{m}^{3}\right)$ & 7900 \\
\hline & Specific heat $(\mathrm{J} / \mathrm{kg} \cdot \mathrm{K})$ & 477 \\
\hline & Thermal conductivity $(\mathrm{W} / \mathrm{m} \cdot \mathrm{K})$ & 15 \\
\hline & Emissivity & 0.22 \\
\hline \multirow{7}{*}{ Silicon } & Density $\left(\mathrm{kg} / \mathrm{m}^{3}\right)$ & 2450 \\
\hline & Specific heat $(\mathrm{J} / \mathrm{kg} \cdot \mathrm{K})$ & $1059(<1685 \mathrm{~K}), 1000(>1685 \mathrm{~K})$ \\
\hline & Thermal conductivity $(\mathrm{W} / \mathrm{m} \cdot \mathrm{K})$ & $24(<1685 \mathrm{~K}), 64(>1685 \mathrm{~K})$ \\
\hline & Dynamic viscosity $(\mathrm{kg} / \mathrm{m} \cdot \mathrm{s})$ & $7 \times 10^{-4}$ \\
\hline & Thermal expansion coefficient $(1 / \mathrm{K})$ & $1.4 \times 10^{-4}$ \\
\hline & Latent heat $(\mathrm{J} / \mathrm{kg})$ & $1.4 \times 10^{6}$ \\
\hline & Melting point $(\mathrm{K})$ & 1685 \\
\hline \multirow{3}{*}{ Argon } & Specific heat $(\mathrm{J} / \mathrm{kg} \cdot \mathrm{K})$ & 521 \\
\hline & Thermal conductivity $(\mathrm{W} / \mathrm{m} \cdot \mathrm{K})$ & $0.01+2.5 \times 10^{-5} \mathrm{~T}$ \\
\hline & Dynamic viscosity $(\mathrm{kg} / \mathrm{m} \cdot \mathrm{s})$ & $8.466 \times 10^{-6}+5.365 \times 10^{-8} \mathrm{~T}-8.682 \times 10^{-12} \mathrm{~T}^{2}$ \\
\hline
\end{tabular}

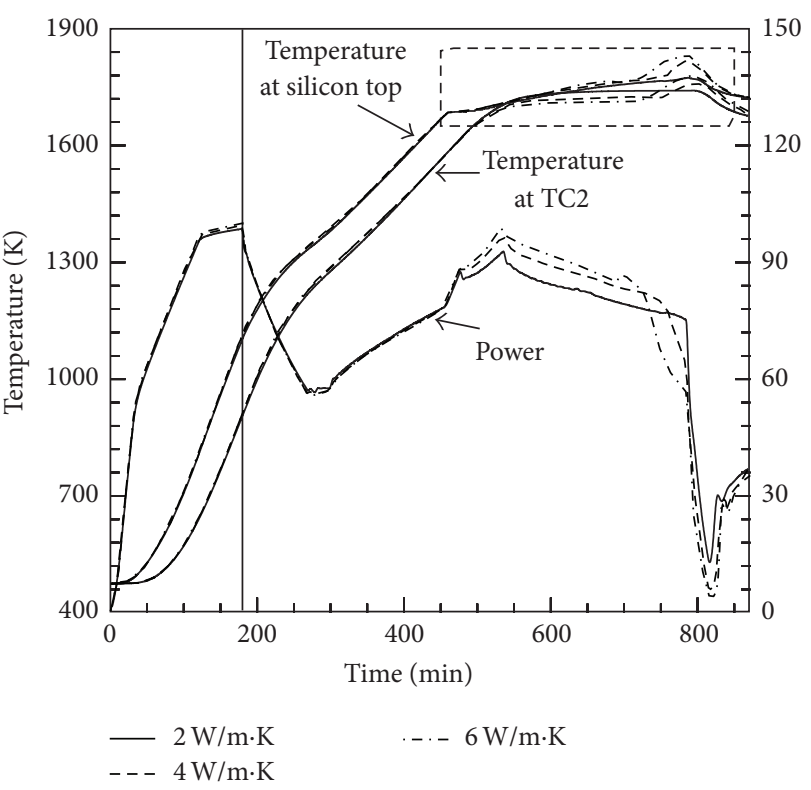

(a)

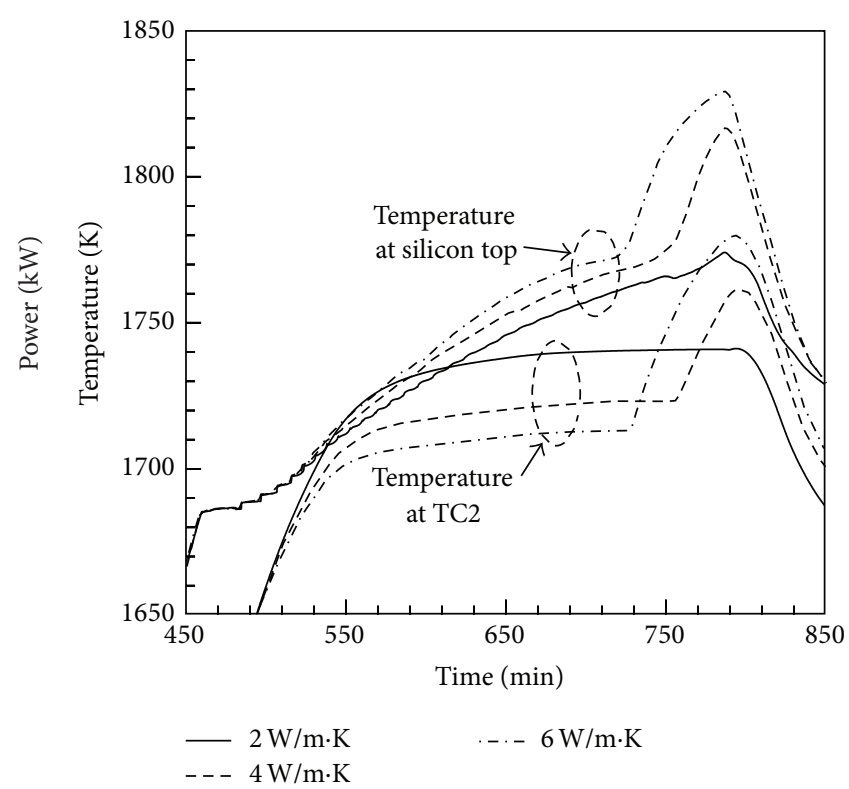

(b)

FIGURE 2: Evolution of process parameters during the heating and melting stages for DS processes with different crucible thermal conductivities: (a) evolutions of temperature and power; (b) partial enlarged view of the dashed rectangle in (a). 


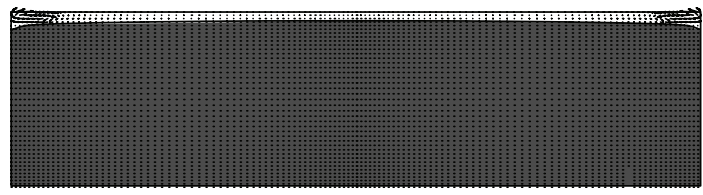

(a1)

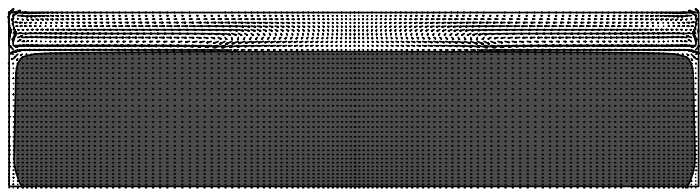

(a2)

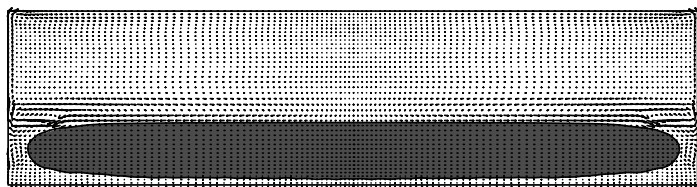

(a3)

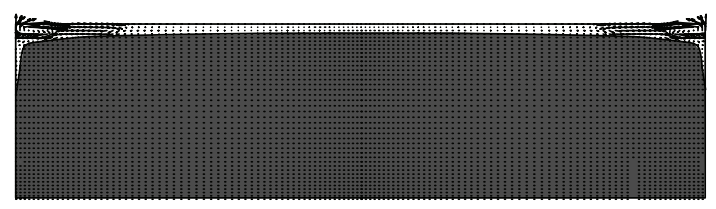

(b1)

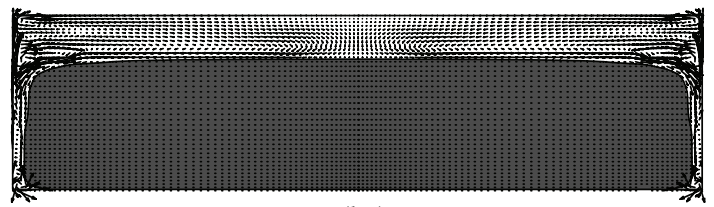

(b2)

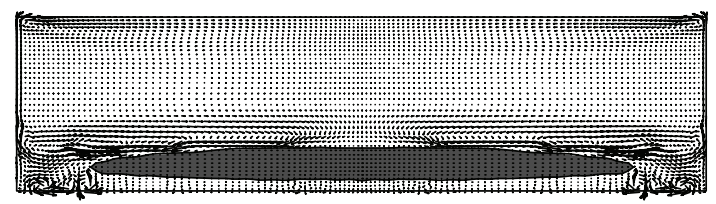

(b3)

FIGURE 3: Melting sequences of silicon feedstock for DS processes with different crucible thermal conductivities: (a1)-(a3) $2 \mathrm{~W} / \mathrm{m} \cdot \mathrm{K}$; (b1)-(b3) $6 \mathrm{~W} / \mathrm{m} \cdot \mathrm{K}$. (al) and (b1): $500 \mathrm{~min}$; (a2) and (b2): $560 \mathrm{~min}$; (a3) and (b3): $700 \mathrm{~min}$.

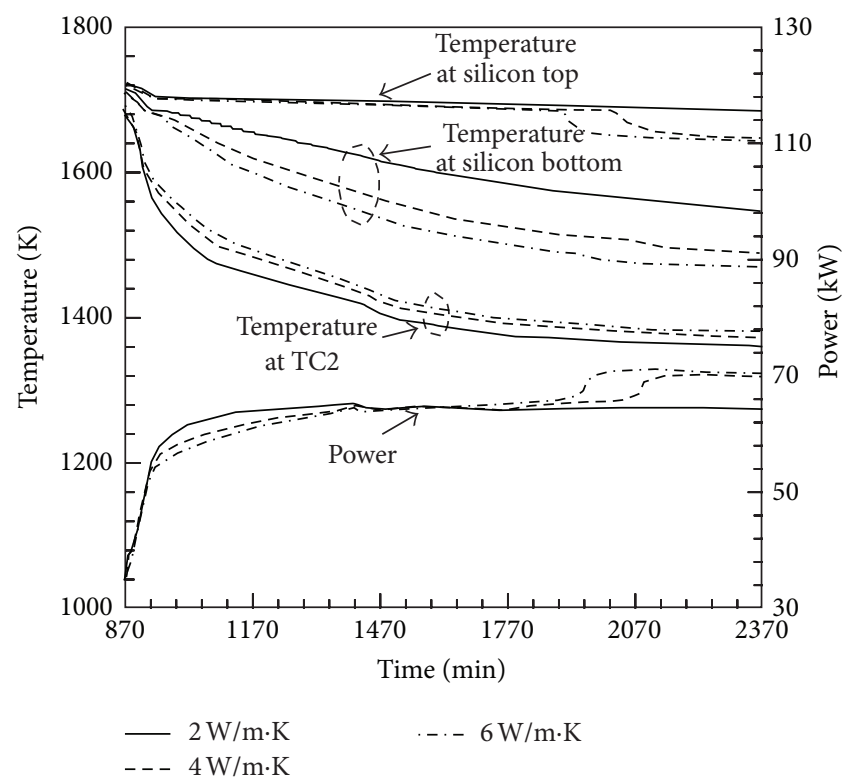

(a)

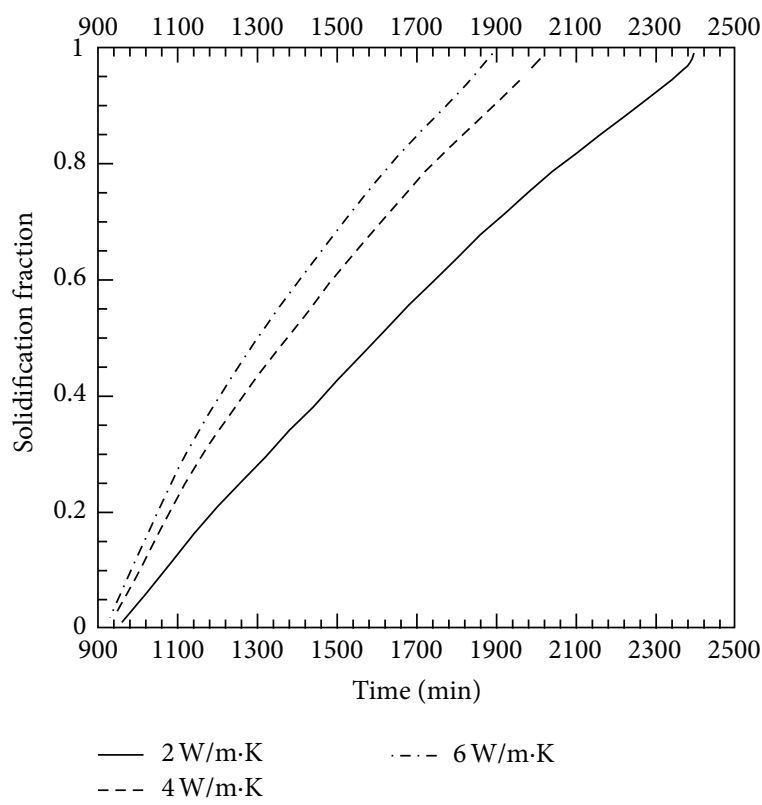

(b)

FIGURE 4: Evolution of process parameters during the growing stage for DS processes with different crucible thermal conductivities: (a) evolutions of temperature and power; (b) evolution of solidification fraction.

Figures 3(a2) and 3(b2). Then, the feedstock located near the crucible bottom wall melts before complete melting, as shown in Figures 3(a3) and 3(b3). The above analyses indicate that the crucible thermal conductivity does not influence the melting sequence too much, though it can change the melting time significantly. This is because the crucible thermophysical properties can influence the amount of heat transfer, but it cannot change the pathway or direction of heat transfer.
3.2. Effect of Crucible Thermal Conductivity in the Growing Stage. Figure 4(a) shows the evolutions of temperature and heating power in the growing stage for DS processes with different crucible thermal conductivities. As shown in the figure, the growing stage lasts from 870 to $2370 \mathrm{~min}$ with the total of $1500 \mathrm{~min}$, and the crucible thermal conductivity can influence the growing parameters significantly. The temperature evolution of TC1 to control the heating power is preset 


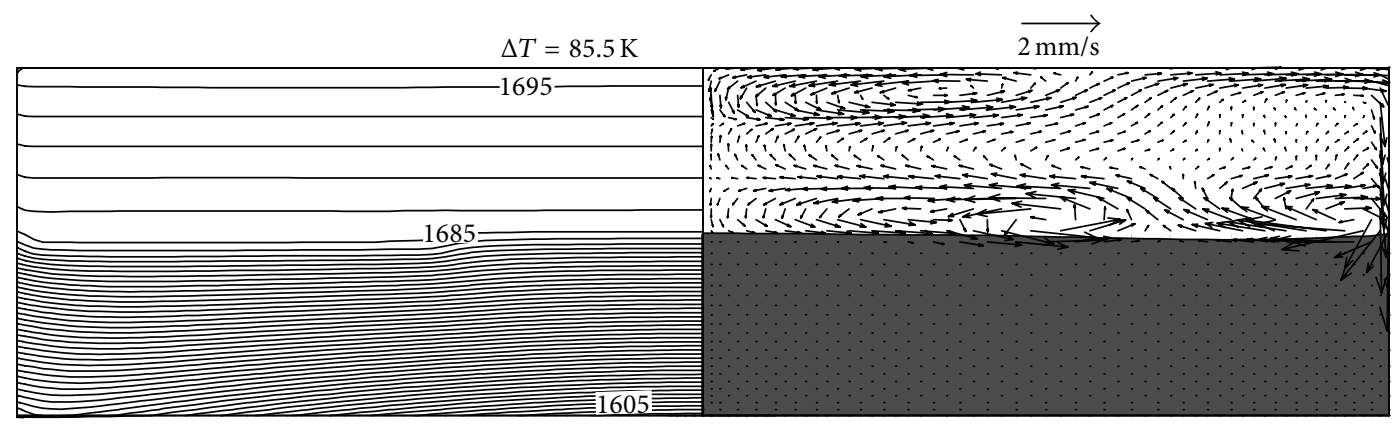

(a)

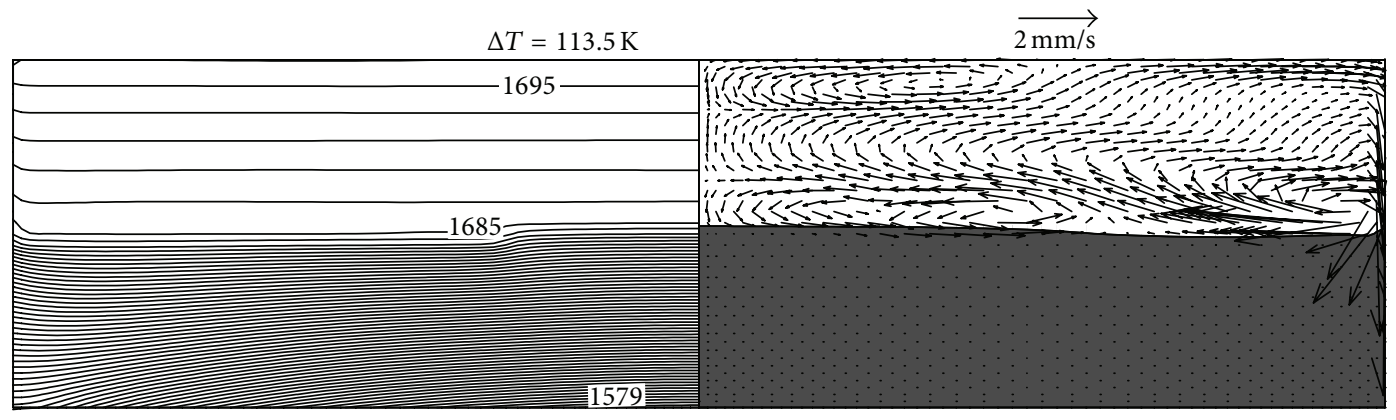

(b)

Figure 5: Temperature distribution (left, $2 \mathrm{~K}$ between isotherms), velocity vector, and melt-crystal interface (right) in the silicon domain under $50 \%$ solidification for DS processes with different crucible thermal conductivities: (a) $2 \mathrm{~W} / \mathrm{m} \cdot \mathrm{K}$; (b) $6 \mathrm{~W} / \mathrm{m} \cdot \mathrm{K}$. $\Delta T$ is the temperature difference along the axis in crystal domain.

the same for all the cases and the crucible thermal resistance increases with the decrease of thermal conductivity. As a result, the temperature at the silicon top surface and that at the silicon bottom surface, both of which are above the crucible bottom wall, are higher for the process with lower crucible thermal conductivity, and the temperature of TC2, which is below the crucible, has the opposite behavior. Due to the blocking effect of crucible bottom wall on the heat transfer, the temperature difference between the silicon top and bottom surfaces, which can represent the vertical heat flux, decreases with the decrease of crucible thermal conductivity. Furthermore, the temperature at the silicon top surface suddenly drops at about 2030 and $1900 \mathrm{~min}$ for the thermal conductivity of 4 and $6 \mathrm{~W} / \mathrm{m} \cdot \mathrm{K}$, respectively, and the heating power rises almost at the same time. This is because the solidification ends and no further latent heat is released. There is no such a turning point for the case of $2 \mathrm{~W} / \mathrm{m} \cdot \mathrm{K}$, as the silicon melt has not been completely solidified by the end of the growing stage.

Figure 4(b) shows the evolution of solidification fraction for the DS processes with different crucible thermal conductivities. The starting times of solidification for the three cases of 2, 4, and $6 \mathrm{~W} / \mathrm{m} \cdot \mathrm{K}$ are 950,930 , and $920 \mathrm{~min}$, respectively. The corresponding ending times are 2400, 2030, and $1900 \mathrm{~min}$, respectively. Therefore, the total times consumed on the silicon crystal growth are 1450, 1100, and $980 \mathrm{~min}$ for the three cases and the average growth rates are 9.9, 13.1, and $14.7 \mathrm{~mm} / \mathrm{h}$, respectively. These data means that increasing the crucible thermal conductivity from 2 to $6 \mathrm{~W} / \mathrm{m} \cdot \mathrm{K}$ can shorten the solidification time by up to $470 \mathrm{~min}$, and the average growth rate can be increased by almost $50 \%$.

To investigate the effect of crucible thermal conductivity on the silicon crystal growth in detail, Figure 5 shows the temperature distribution, velocity vector, and melt-crystal interface in the silicon domain for the cases of 2 and $6 \mathrm{~W} / \mathrm{m} \cdot \mathrm{K}$ under the condition of $50 \%$ solidification. The temperature distributions are shown on the left side of the figures. The value of $1685 \mathrm{~K}$ is the melting point and it corresponds to the melt-crystal interface. More latent heat is released at the melt-crystal interface for large growth rate under the condition of large crucible thermal conductivity. Therefore, the vertical temperature difference along the crystal axis in Figure $5(\mathrm{~b})$ is as high as $113.5 \mathrm{~K}$, whereas it is only $85.5 \mathrm{~K}$ in Figure 5(a). The large temperature difference may lead to high thermal stress in the silicon ingots. Due to the large thermal conductivity, latent heat is also easily released through the crucible side wall. As a result, the isotherm of melting point in Figure 5(b) is more curved close to the crucible side wall, which means high horizontal temperature gradient in this region. The melt velocity vector and melt-crystal interface are shown on the right side of the figures. There are three vortices in the silicon melt and the main clockwise flow in Figure 5(b) is stronger, as the horizontal temperature gradient and the corresponding thermal buoyancy force near the crucible side wall are larger. The overall melt-crystal interface becomes a little more convex with the increase of crucible thermal conductivity, as the strong clockwise flow takes more hot melt along the crucible side wall and pushes the outer part 


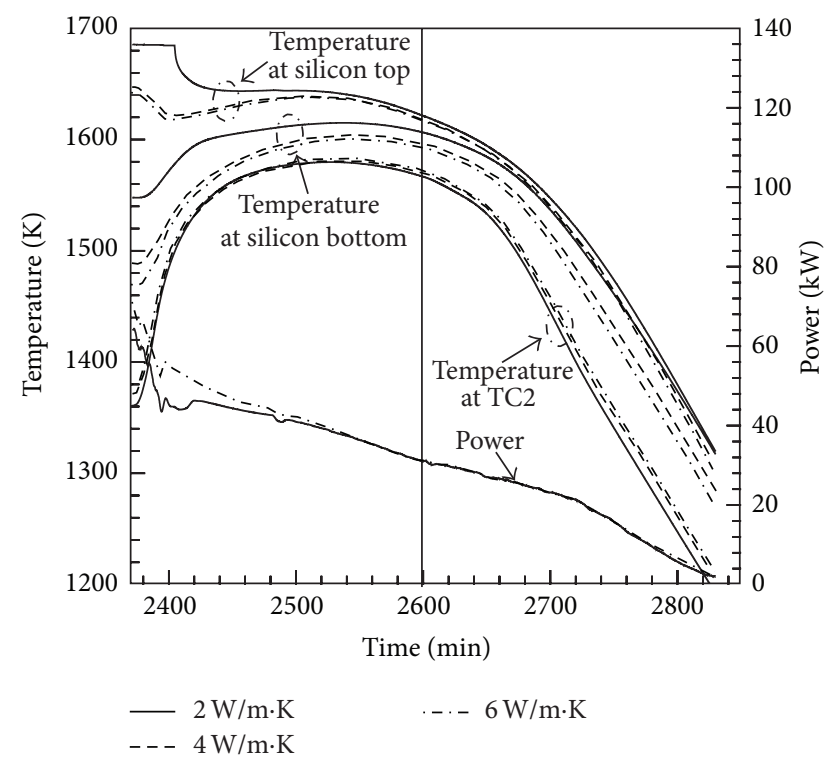

FIGURE 6: Evolution of process parameters during the annealing and cooling stages for DS processes with different crucible thermal conductivities.

of the interface downwards. However, the local melt-crystal interface close to the crucible side wall is more concave for large crucible thermal conductivity. This is consistent with the temperature contours in this region and it can lead to serious dislocation propagation from the crucible side wall.

\subsection{Effect of Crucible Thermal Conductivity in the Annealing} and Cooling Stages. Figure 6 shows the evolution of temperature and heating power in the annealing and cooling stages for DS processes with different crucible thermal conductivities. The vertical thin solid line is the transition point of these two stages. The temperature at the silicon top surface decreases and that at the silicon bottom surface increases during the annealing stage to reduce the temperature difference and thermal stress in the silicon ingots. Then, the temperature decreases rapidly to cool the silicon ingots during the cooling stage. Similar to the growing stage, the temperature difference between the silicon top and bottom increases with the increase of crucible thermal conductivity and that between the silicon top and TC2 has the opposite behavior. For the special case of $2 \mathrm{~W} / \mathrm{m} \cdot \mathrm{K}$, the heating power before $2500 \mathrm{~min}$ is significantly smaller than the other two cases, as the solidification is not completed until $2400 \mathrm{~min}$ and the latent heat releasing during this process makes the heating power lower. For the regular cases of 4 and $6 \mathrm{~W} / \mathrm{m} \cdot \mathrm{K}$, the difference between the power consumptions is very small, which indicates that the crucible thermal conductivity cannot influence the heating power significantly during the annealing and cooling stages.

Figure 7 shows the temperature distributions in the silicon ingots at the end of annealing and during cooling for DS processes with different crucible thermal conductivities. The axial temperature difference for annealing in Figure $7(\mathrm{a})$ is $14.9 \mathrm{~K}$, which is much smaller than the value of $25.0 \mathrm{~K}$ in Figure 7 (b). Therefore, large crucible thermal conductivity is likely to lead to high thermal stress in the annealing process. During the cooling stage, the heating power gradually decreases to zero and the side insulation is wide open. This makes silicon domain the hottest in the DS furnace and annular isotherms are formed in the ingots. More heat is lost through the crucible bottom and side walls with the increase of thermal conductivity. As a result, the hottest annular region moves upwards in Figure 7(b) and the temperature distributions are different in the two figures. The values of temperature on the right side of Figure 7(b) are significantly lower than those in Figure $7(\mathrm{a})$, as the large crucible thermal conductivity leads to fast heat loss from the hot silicon domain to its surroundings. The different distributions of thermal field during cooling can also affect the evolution of thermal stress.

\subsection{Discussions on Choosing Crucible Thermal Conductivity.} One issue that needs further discussion is the application of crucible with appropriate thermal conductivity in the real industrial production process. In this numerical study, the total electrical energy consumptions during the entire DS process are 2854,2885 , and $2894 \mathrm{~kW} \cdot \mathrm{h}$ for the three cases, which means that applying crucible with large thermal conductivity will increase the energy consumption. The above data is based on the assumption that all the processes use the same TCl curve to control the heating power. However, it is known in Figures 2 and 4 that increasing the crucible thermal conductivity from 2 to $6 \mathrm{~W} / \mathrm{m} \cdot \mathrm{K}$ can shorten the melting and growing time by 65 and $470 \mathrm{~min}$, respectively. This means the TCl setting should be adjusted to shorten the melting and growing stages for large thermal conductivity. Therefore, applying the crucible with large thermal conductivity in the real industrial DS process can help to save both production time and electrical energy. However, the disadvantage is that using a crucible with large thermal conductivity can lead to locally concave melt-crystal interface shape close to the crucible side wall and large temperature gradient in the silicon ingots, both of which increase the possibility of large thermal stress and dislocation propagation. With further analysis, it is known that the crucible bottom wall influences the vertical heat release related to the silicon crystal growth, and the side wall influences the horizontal heat release related to the melt-crystal interface shape close to it. Therefore, it is preferred to use a crucible with large thermal conductivity at the bottom wall and small thermal conductivity at the side wall in the industrial DS process. This will guarantee relatively large growth rate, low energy consumption, and flat melt-crystal interface shape. It is feasible to manufacture such a crucible by adjusting the porosity or using composited materials [13].

\section{Conclusions}

We carried out transient global simulations of heating, melting, growing, annealing, and cooling stages in the DS process to investigate the influence of crucible thermal conductivity on global heat transfer and silicon crystal growth. It is found 


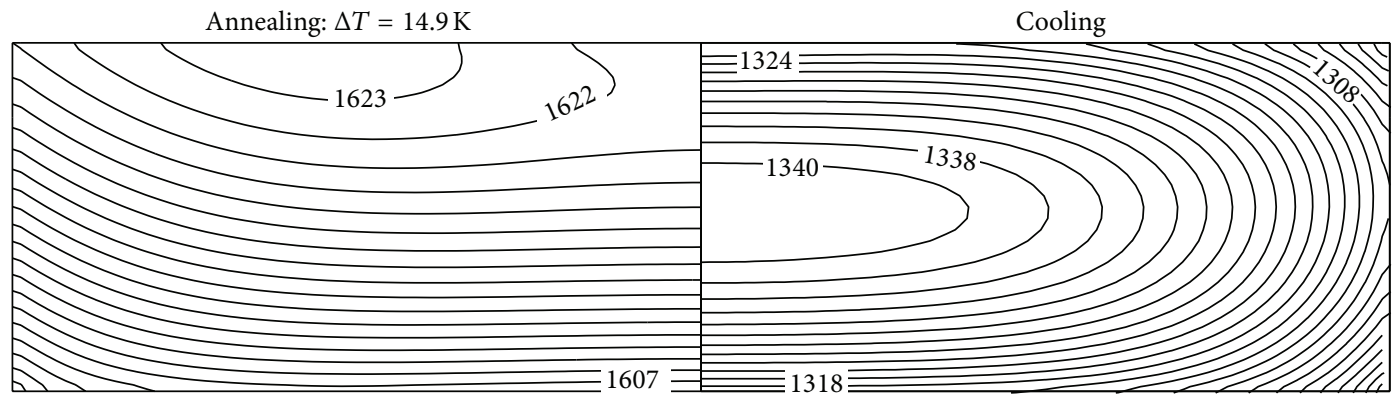

(a)

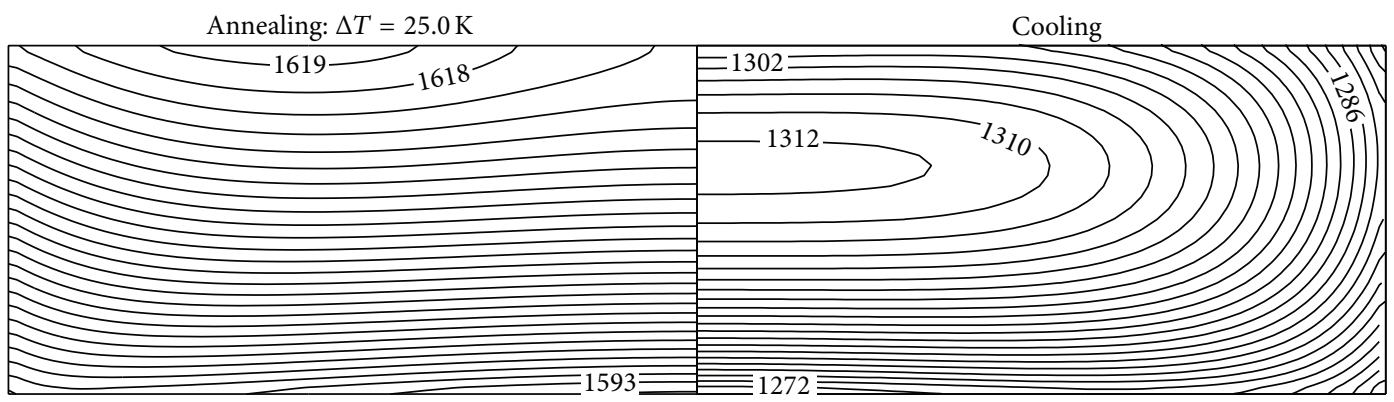

(b)

FIgURE 7: Temperature distribution in the silicon ingots at the end of annealing (left, $1 \mathrm{~K}$ between isotherms) and during cooling (right, $2 \mathrm{~K}$ between isotherms) for DS processes with different crucible thermal conductivities: (a) $2 \mathrm{~W} / \mathrm{m} \cdot \mathrm{K}$; (b) $6 \mathrm{~W} / \mathrm{m} \cdot \mathrm{K}$.

that increasing the thermal conductivity from 2 to $6 \mathrm{~W} / \mathrm{m} \cdot \mathrm{K}$ can decrease the melting time by $65 \mathrm{~min}$, whereas it has little effect on the melting sequence. In the crystal growth stage, increasing the crucible thermal conductivity from 2 to $6 \mathrm{~W} / \mathrm{m} \cdot \mathrm{K}$ can shorten the growing time by up to $470 \mathrm{~min}$, which means that large thermal conductivity is helpful in saving both production time and electrical energy. However, the high temperature gradient and locally concave meltcrystal interface under the condition of large thermal conductivity are likely to cause high thermal stress and dislocation propagation during crystal growth. In the annealing and cooling stages, the crucible thermal conductivity can also affect the temperature distributions in the silicon ingots. Therefore, it should be considered to use a crucible with large and small thermal conductivity at the bottom and side walls, respectively.

\section{Competing Interests}

The authors declare that there is no conflict of interests regarding the publication of this paper.

\section{Acknowledgments}

This research was supported by the National Natural Science Foundation of China (no. 51406156), Fundamental Research Funds for the Central Universities of China, and China Postdoctoral Science Foundation (no. 2013M540747).

\section{References}

[1] Fraunhofer Institute for Solar Energy Systems ISE with Support of PSE AG, Photovoltaics Report, Fraunhofer Institute for Solar Energy Systems ISE, Freiburg, Germany, 2015.

[2] Semi, "International technology roadmap for photovoltaic," 2015, http://www.itrpv.net.

[3] Z. Li, L. Liu, W. Ma, and K. Kakimoto, "Effects of argon flow on heat transfer in a directional solidification process for silicon solar cells," Journal of Crystal Growth, vol. 318, no. 1, pp. 298303, 2011.

[4] Z. Y. Li, L. J. Liu, W. C. Ma, and K. Kakimoto, "Effects of argon flow on impurities transport in a directional solidification furnace for silicon solar cells," Journal of Crystal Growth, vol. 318, no. 1, pp. 304-312, 2011.

[5] P. Rudolph, "Transport phenomena of crystal growth-heat and mass transfer," Selected Topics on Crystal Growth, vol. 1270, pp. 107-132, 2010.

[6] J. Wei, H. Zhang, L. Zheng, C. Wang, and B. Zhao, "Modeling and improvement of silicon ingot directional solidification for industrial production systems," Solar Energy Materials and Solar Cells, vol. 93, no. 9, pp. 1531-1539, 2009.

[7] J. Y. Li, M. Liu, Y. Tan, and L. S. Wen, "Effect of the silicon nitride coating of quartz crucible on impurity distribution in ingotcast multicrystalline silicon," International Journal of Applied Ceramic Technology, vol. 10, no. 1, pp. 40-44, 2013.

[8] C. Modanese, M. Di Sabatino, M. Syvertsen, and L. Arnberg, "Chemical bulk properties of multicrystalline silicon ingots for solar cells cast in silicon nitride crucibles," Journal of Crystal Growth, vol. 354, no. 1, pp. 27-33, 2012. 
[9] H. Miyazawa, L. Liu, and K. Kakimoto, "Numerical investigation of the influence of material property of a crucible on interface shape in a unidirectional solidification process," Crystal Growth and Design, vol. 9, no. 1, pp. 267-272, 2009.

[10] X. J. Chen, S. Nakano, and K. Kakimoto, "3D numerical analysis of the influence of material property of a crucible on stress and dislocation in multicrystalline silicon for solar cells," Journal of Crystal Growth, vol. 318, no. 1, pp. 259-264, 2011.

[11] M. P. Bellmann, E. A. Meese, M. Syvertsen, A. Solheim, H. Sørheim, and L. Arnberg, "Silica versus silicon nitride crucible: influence of thermophysical properties on the solidification of multi-crystalline silicon by Bridgman technique," Journal of Crystal Growth, vol. 318, no. 1, pp. 265-268, 2011.

[12] V. Schneider, C. Reimann, J. Friedrich, and G. Müller, "Nitride bonded silicon nitride as a reusable crucible material for directional solidification of silicon," Crystal Research and Technology, vol. 51, no. 1, pp. 74-86, 2016.

[13] L. L. Zhao, T. Z. Lv, and Q. S. Zhu, " $\mathrm{Si}_{3} \mathrm{~N}_{4} /$ fused quartz composite crucible with enhanced thermal conductivity for multicrystalline silicon ingot growth," Journal of Crystal Growth, vol. 415, pp. 51-56, 2015.

[14] Z. Li, L. Liu, X. Liu, Y. Zhang, and J. Xiong, "Effects of argon flow on melt convection and interface shape in a directional solidification process for an industrial-size solar silicon ingot," Journal of Crystal Growth, vol. 360, no. 1, pp. 87-91, 2012.

[15] V. R. Voller and C. Prakash, "A fixed grid numerical modelling methodology for convection-diffusion mushy region phasechange problems," International Journal of Heat and Mass Transfer, vol. 30, no. 8, pp. 1709-1719, 1987.

[16] Z. Li, L. Liu, X. Liu, Y. Zhang, and J. Xiong, "Heat transfer in an industrial directional solidification furnace with multi-heaters for silicon ingots," Journal of Crystal Growth, vol. 385, pp. 9-15, 2014.

[17] Y.-Y. Teng, J.-C. Chen, C.-W. Lu, H.-I. Chen, C. Hsu, and C.-Y. Chen, "Effects of the furnace pressure on oxygen and silicon oxide distributions during the growth of multicrystalline silicon ingots by the directional solidification process," Journal of Crystal Growth, vol. 318, no. 1, pp. 224-229, 2011. 

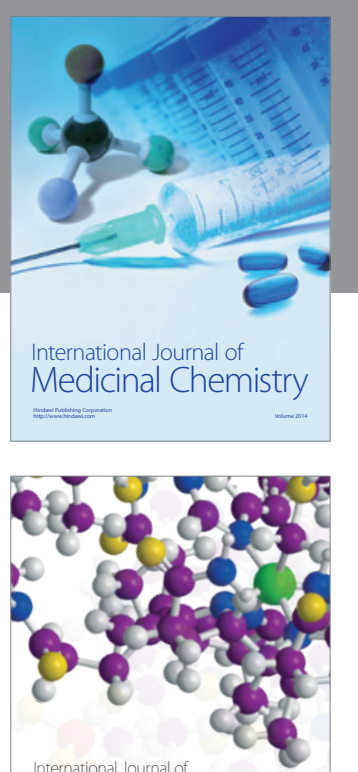

Carbohydrate Chemistry

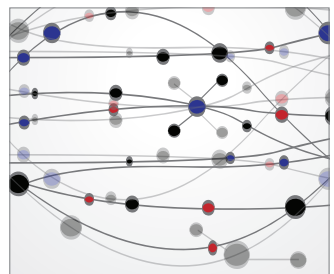

The Scientific World Journal
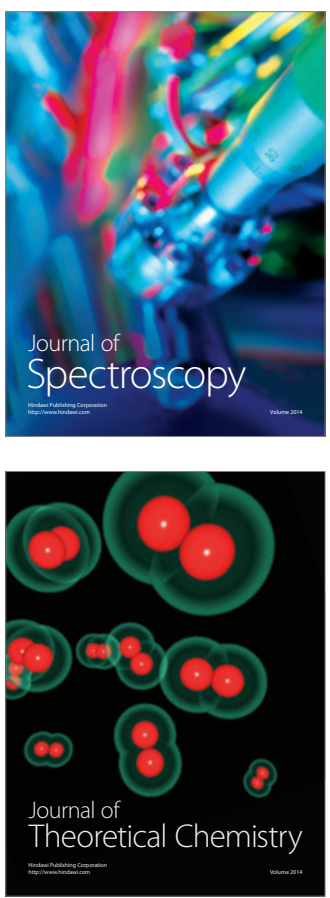
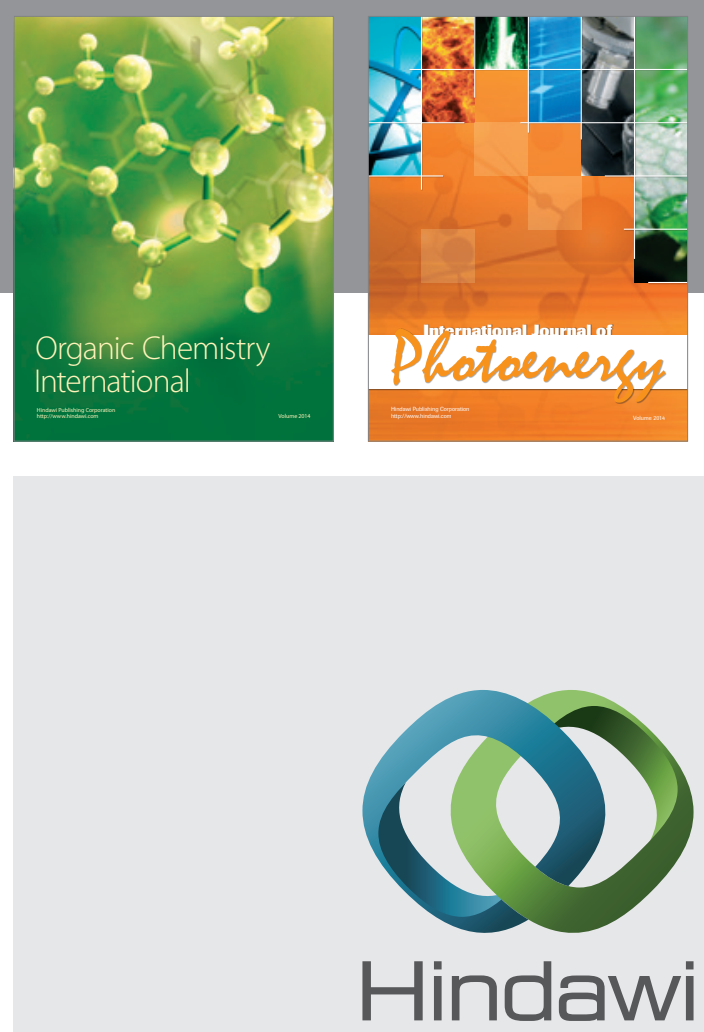

Submit your manuscripts at

http://www.hindawi.com

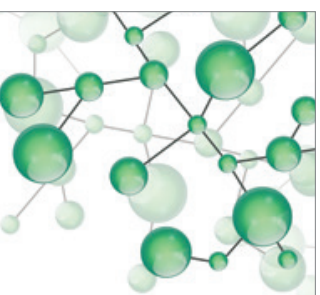

International Journal of

Inorganic Chemistry

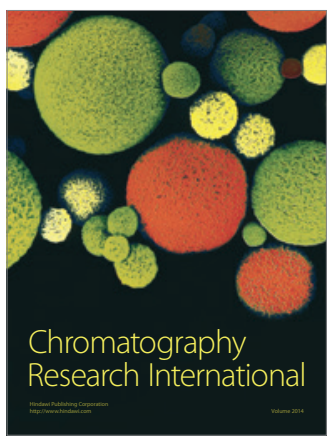

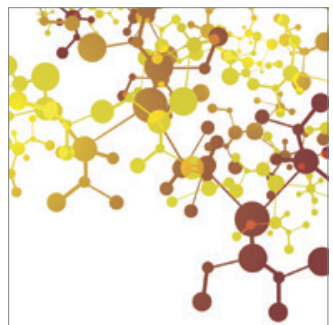

Applied Chemistry
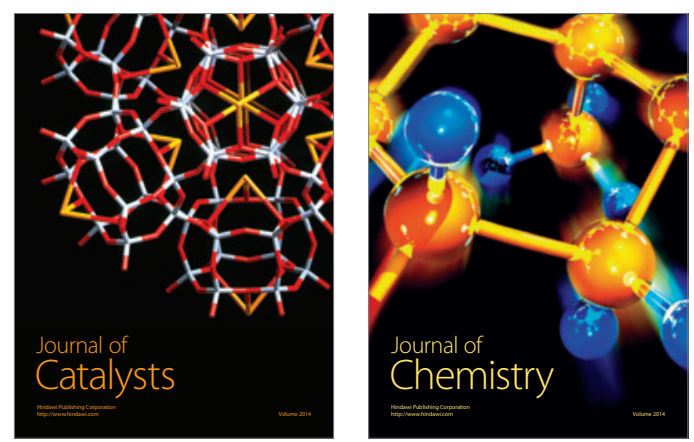
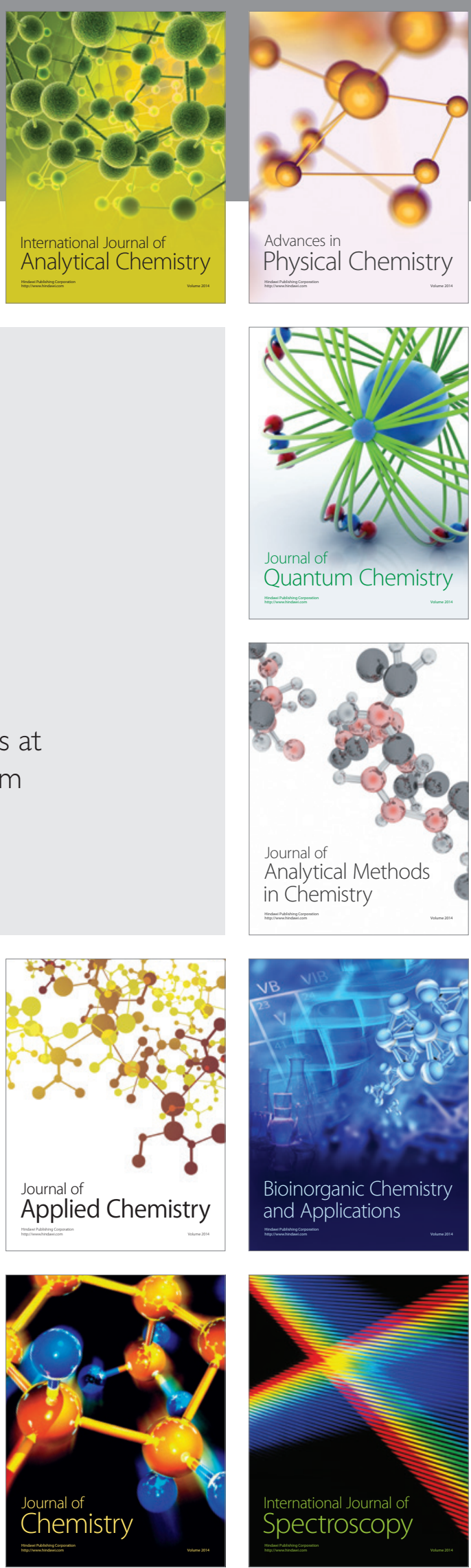